\title{
Study protocol for a diagnostic randomized clinical trial to evaluate the effect of the use of two clinical criteria in the assessment of caries lesions around restorations in adults: the Caries Cognition and Identification in Adults (CaClA) trial
}

Cácia Signori', Bruna Lorena Pereira Moro², Juliana Lays Stolfo Uehara', Vitor Henrique Digmayer Romero', Elenara Ferreira de Oliveira', Mariana Minatel Braga ${ }^{2}$, Fausto Medeiros Mendes ${ }^{2}$, Maximiliano Sérgio Cenci ${ }^{1 *}$ (D) and CaCIA Collaborative Group

\begin{abstract}
Background: The assessment of restored teeth in dentistry remains a challenge, mainly related to the detection of caries around restorations. There is a diversity of clinical criteria available to assess the caries lesions, resulting in differences in the dentists' diagnosis and treatment decisions. In addition, there is a lack of evidence regarding the best criteria to detect caries lesions around the restorations. Thus, the present protocol aims to evaluate the effect of using 2 visual criteria to assess restored teeth on the outcomes related to oral health in adults.

Methods: The design protocol of the Caries Cognition and Identification in Adults trial correspond to a triple-blind randomized, controlled clinical trial with parallel-groups. Two groups will be compared: patients who will receive the diagnosis and treatment decision according to FDI (World Dental Federation) criteria-FDI group; and patients who will receive diagnosis and treatment decision according to the "Caries Associated with Restorations or Sealants" criteria defined by the International Caries Classification and Management System (ICCMS group). The participants will be followed up after $6,12,18,24$, and 60 months, and the restoration failure will be the primary outcome. The analysis will be conducted through Cox regression with shared frailty. The impact of oral health on quality of life and the costeffectiveness of the methods used will be the secondary outcomes. Two-tailed analyzes will be used, considering a level of significance of $5 \%$.
\end{abstract}

Discussion: This is the first clinical trial to assess the effect of using two visual methods to detect caries lesions around restorations on the outcomes related to oral health in adults. The findings of this study will define what is the best diagnostic strategy for the assessment of caries around restorations in permanent teeth.

Trial registration NCT03108586 (registered 11 April 2017).

\footnotetext{
*Correspondence: cencims@gmail.com; Maximiliano.cenci@ufpel.edu.br

${ }^{1}$ Graduate Program in Dentistry, Federal University of Pelotas, Pelotas, RS,

Brazil

Full list of author information is available at the end of the article
}

(c) The Author(s) 2020. Open Access This article is licensed under a Creative Commons Attribution 4.0 International License, which permits use, sharing, adaptation, distribution and reproduction in any medium or format, as long as you give appropriate credit to the original author(s) and the source, provide a link to the Creative Commons licence, and indicate if changes were made. The images or other third party material in this article are included in the article's Creative Commons licence, unless indicated otherwise in a credit line to the material. If material is not included in the article's Creative Commons licence and your intended use is not permitted by statutory regulation or exceeds the permitted use, you will need to obtain permission directly from the copyright holder. To view a copy of this licence, visit http://creativecommons.org/licenses/by/4.0/. The Creative Commons Public Domain Dedication waiver (http://creativeco mmons.org/publicdomain/zero/1.0/) applies to the data made available in this article, unless otherwise stated in a credit line to the data. 
Keywords: Caries detection, Dental caries, Restorations, Secondary caries, Caries around restorations, Diagnosis, Visual inspection, Dental treatment, Randomized clinical trial

\section{Background}

Secondary caries was recognized as one of the conditions on dentistry of the highest potential for improving future restorative treatment over the next 20 years [1]. Secondary caries is the designation given to a caries lesion adjacent to a restoration [2]. The scientific literature reports this condition as the main reason for restorations failures [2-5]. A recent review reported that the replacement of failed restorations due to secondary caries represents a high number of the restorations placed by the dentists (28.5-59\% of cases). In contrast, the number of failed restorations due to secondary caries is notedly lower $(2-3 \%)$ in controlled clinical trials [3, 4], which raises doubts about the real prevalence of this condition and the possibility of overtreatment. Besides, the dentists show heterogeneity in the treatment decision-making regarding secondary caries $[6,7]$.

The correct diagnosis of caries around the restorations is often a challenge for dentists due to aspects as the presence of gaps between the restoration and tooth surface, marginal staining, and due to the development on challenging areas of assessment, such as interproximal areas [8]. Some of these aspects can lead to an erroneous detection of caries lesion $[9,10]$. Different clinical criteria have been used in the visual detection of caries around restorations [11], which may imply different interpretations about what is a secondary caries lesion. Among these criteria, two are highlighted due to the current use in research and clinic: the International Dental Federation (FDI) criteria [12] and Caries Associated with Restorations or Sealants (CARS) criteria, described in the International Caries Classification and Management System (ICCMS) [13].

Nevertheless, all studies on methods for caries detection around restorations are cross-sectional accuracy studies [11, 14]. Moreover, most studies fail to present clinical relevance and report patient-centered outcomes [11]. No randomized clinical trial has been conducted to test the best method to detect caries around restorations. Thus, we will run a randomized clinical trial to investigate the best approach to the diagnosis and decision of treatment of restorations in adults. The present protocol will aim to evaluate the effect of using 2 visual criteria, FDI and CARS criteria to assess restored teeth on the outcomes related to oral health in adults.

\section{Methods}

Trial design

This is a triple-blind randomized, controlled, parallelgroup clinical trial. Two groups will be compared: patients who will receive the diagnosis and treatment decision according to FDI criteria [12]-FDI group; and patients who will receive diagnosis and treatment decision according to the "Caries Associated with Restorations or Sealants" (CARS) criteria from ICCMS [13]-ICCMS group. The trial-Caries Cognition and Identification in Adults (CaCIA) trial-has been registered with ClinicalTrial.gov (NCT03108586) and is currently in the active phase. The Standard Protocol Items for Clinical Trials (SPIRIT) were used to guide the present protocol as detailed in the Additional file 1: Appendix (appendix 1).

\section{Participants, interventions, and outcomes Setting}

The study will be conducted at the clinic at the School of Dentistry of the Federal University of Pelotas (UFPel). The patients (18 to 60 years old) will be randomly selected from a list of patients seeking dental treatment at the School of Dentistry.

\section{Eligibility: inclusion and exclusion criteria}

The inclusion criteria will consider the following:

a patients who seek dental treatment at the School of Dentistry;

b are aged 18 to 60 years;

c patients who present at least one restoration of composite resin or amalgam on a permanent posterior tooth.

The exclusion criteria will consider the following:

a patients who refuse to participate in the research;

b patients who present systemic conditions or chronic diseases that require differentiated care and followup. These cases will be referred to the specific services available at the School of Dentistry.

c restorations on teeth with conditions as fistula, abscess, pulp exposure, history of spontaneous dental pain, or mobility will not be included. 


\section{Interventions}

Firstly, all patients' dental surfaces will be examined according to the International Caries Detection and Assessment System (ICDAS) [13]. Patients meeting the inclusion criteria will be classified into subgroups. The individuals will be classified according to caries experience using the Decayed, Missing, Filled permanent Teeth (DMF-T) in 2 groups: index less or equal to 4 , or index greater than 4; and also, according to the caries activity (with or without caries activity), for later block stratification.

In this first appointment, a questionnaire will be applied to assess the impact of oral health on adults' quality of life. The instrument used will be the validated Brazilian version of the Oral Health Impact Profile-14 (OHIP-14) questionnaire [15].

The participants will be allocated into two groups (Fig. 1) according to the strategy used to diagnose and determine the treatment for caries lesions around restorations.

a FDI group Diagnosis and treatment decision based on the International Dental Federation (FDI) criteria (Fig. 2). b Experimental group Diagnosis and treatment decision according to Caries Associated with Restorations or Sealants (CARS) detection criteria, described in the ICCMS (Figs. 3, 4).

A calibrated examiner will perform a clinical examination of the restorations. The calibration was conducted in two phases. In phase I, a series of photos on restorations with marginal defects were projected in a television in a dark room for the examiner and one expert in restorative dentistry with training and experience in the diagnosis of restorations (gold standard). The discussion of the cases was performed. Phase II was completed at the clinic; both examiner and gold standard examined a total of 20 patients, attributing the diagnosis and treatment according to FDI and CARS for each case. The answers were compared in the end, and disagreements were discussed.

In the clinical trial, after the clinical examination, the calibrated examiner will establish the treatment plan, according to the treatment indications of the criteria in which the patients were allocated. The same examiner will re-evaluate the restorations according to the other criteria. However, this procedure will only serve to future

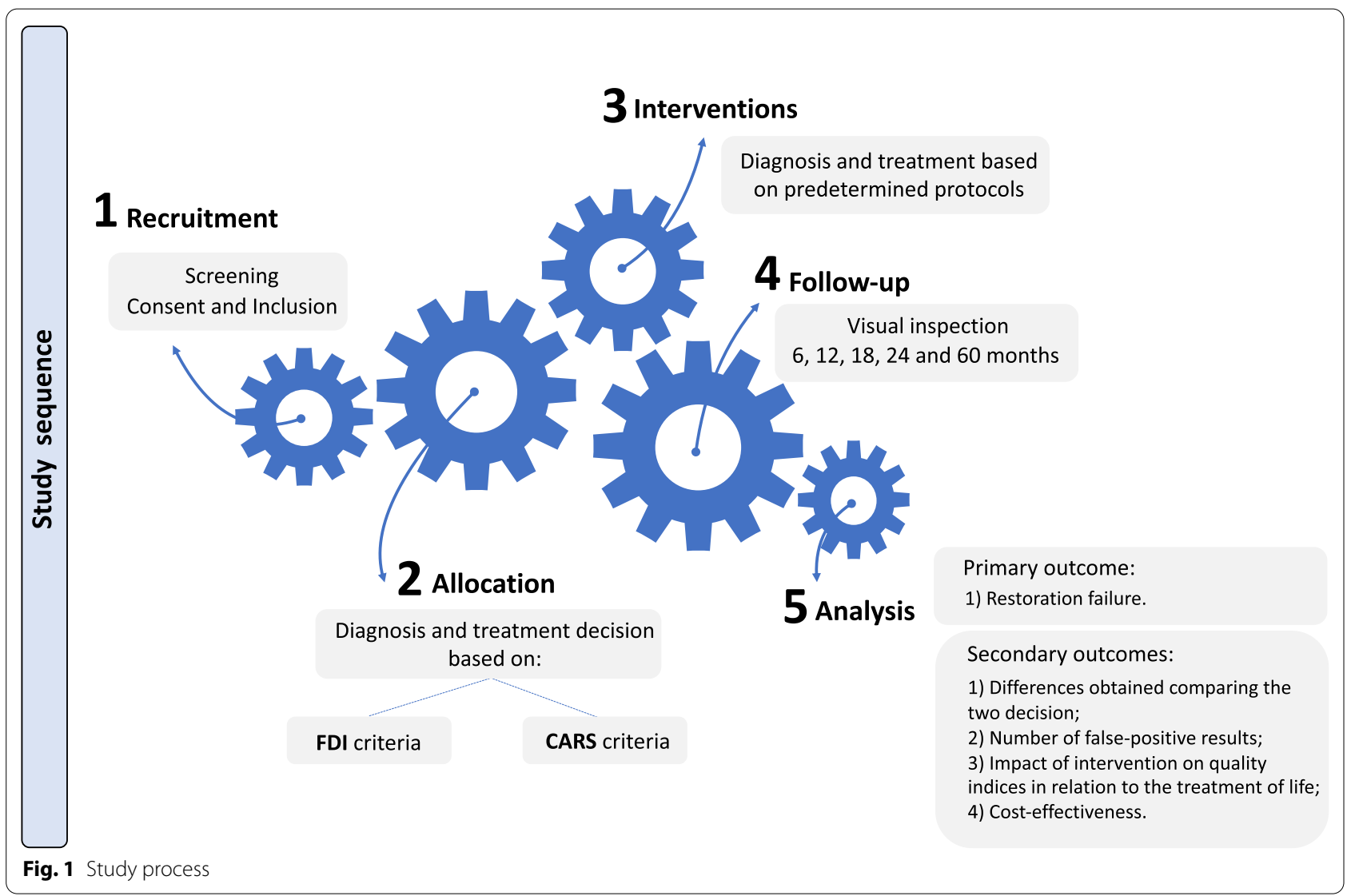




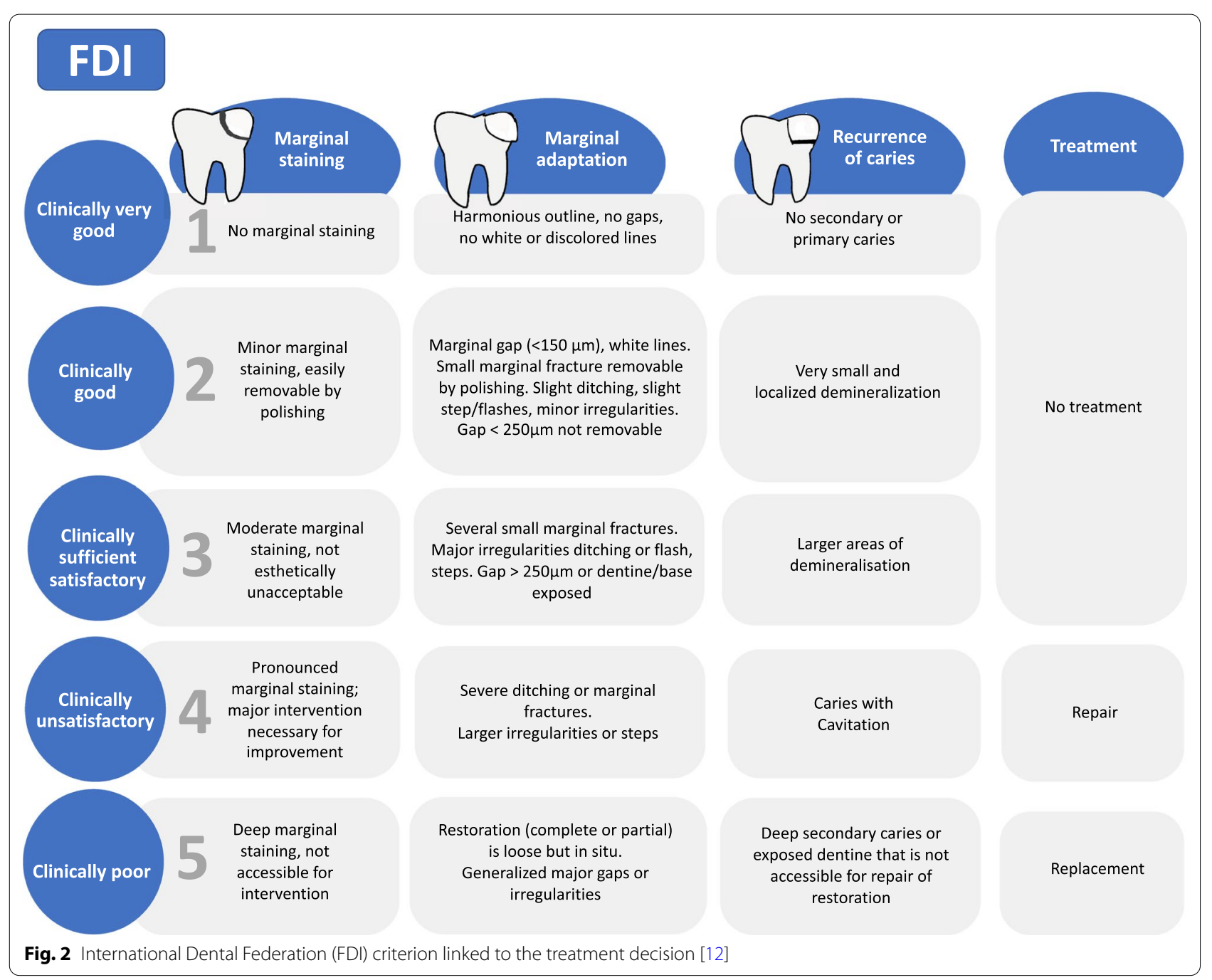

comparison among the methods. This new re-evaluation will not influence the classification and treatment proposed by the first criterion used.

The tests will be conducted in a dental chair under lighting after the teeth are cleaned with a low-rotation micromotor, rubber cup, and Robinson brush using prophylactic paste. The exams will be performed with a dental mirror and a ballpoint probe. To assess the restorations of patients allocated in the FDI group, all surfaces will be dried before evaluation [12]. For the assessment of the experimental group's surfaces, the teeth will be evaluated wet and then dry for $5 \mathrm{~s}$ using the triple syringe, according to the protocol established by the ICCMS [13].

\section{Dental treatment protocols}

The restorations, therefore, will be submitted to the proposed treatment according to the first evaluation performed. These treatments will be performed according to predefined protocols by operators blinded to the criterion used to reach the treatment decision.

In all situations, the carious tissue, if present, will be removed, as well as the dental restorations, when indicated.

Both repair and replacement of restorations will be performed following the adhesive protocol described by the manufacturer (Adper Scotchbond Multi-Purpose, 3M ESPE, USA) to the use of resin restorations. The conventional composite resin (Filtek Z350 XT, 3M ESPE, USA) will be inserted on the cavity using increments. Besides the proposed treatment for restorations, other necessary treatments for the patient will also be performed. Additional treatments (not involving repairs/replacements) will be planned/defined by the operator responsible for the patient's initial clinical examination. 


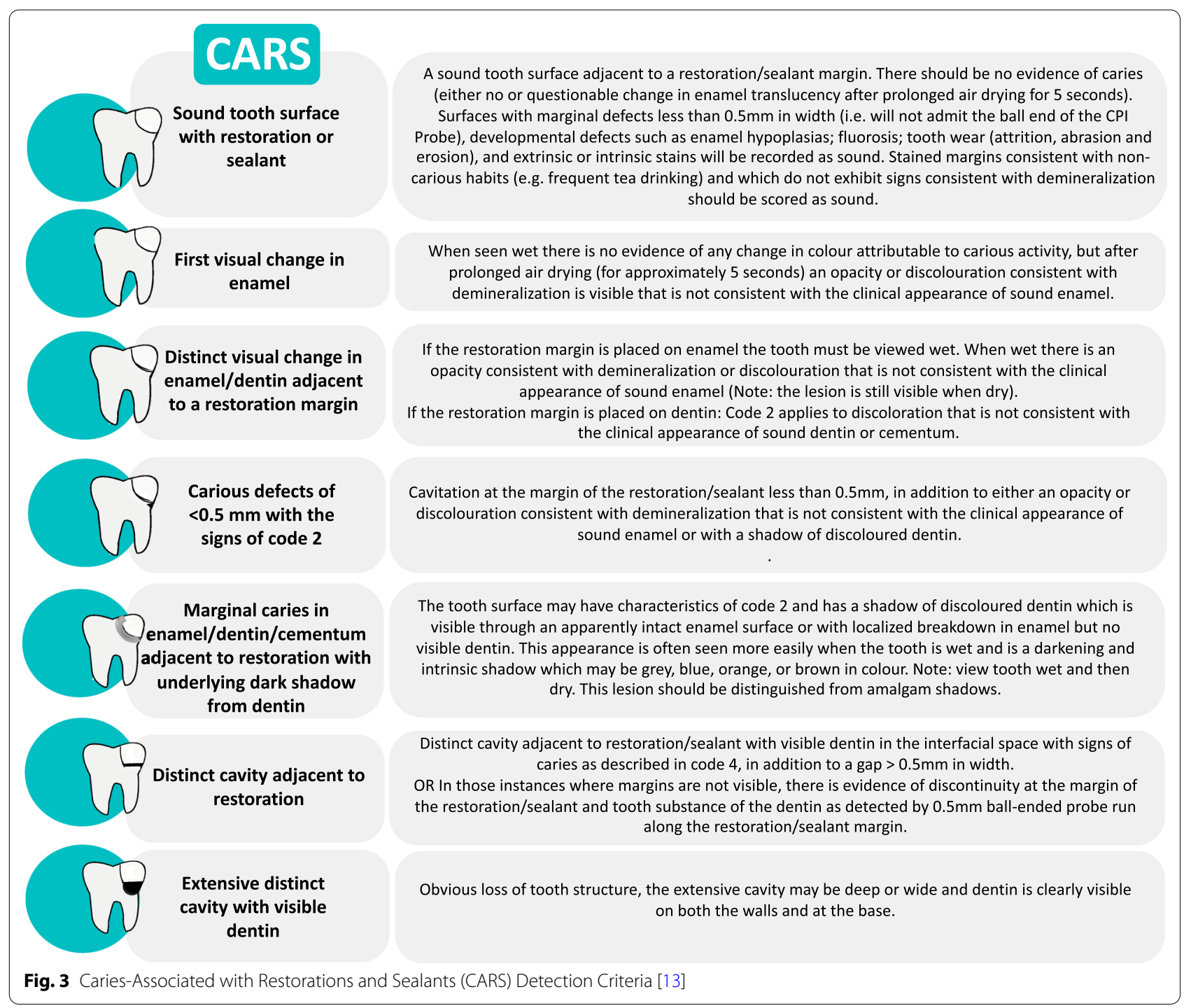

\section{Follow-up visits}

After completing the treatment performed at the last restoration of each participant, they will return to evaluate the outcomes after $6,12,18,24$, and 60 months.

The restorations will be evaluated through clinical inspection (mirror and ballpoint probe) by a previously calibrated examiner. The treatment needs will be established according to the demands of the patients. The examiner will be blind concerning previous allocation groups and previously performed treatments. If the patient needs further treatment-related or not to restorations, it will be performed.

The instrument OHIP-14 will be reapplied 1 week after the patients receive all the interventions needed, at 24 months and 60 months, to assess the impact on the long-term quality of life.

\section{Outcomes}

The primary outcome will be restoration failure. The secondary outcomes will be the differences obtained comparing the two indices in relation to the treatment decision, the number of false-positive results (cases initially indicated to repair or replacement, in which during the intervention no decayed tissue was found), the impact of the intervention on quality of life and cost-effectiveness.

\section{Participant timeline}

The study will be recruiting patients from October 2016 to February 2020. The study's enrollment for each participant will lead approximately 61 months, estimating 1 month of treatment and 60 months of follow-up. The study phases are presented in Fig. 5. 


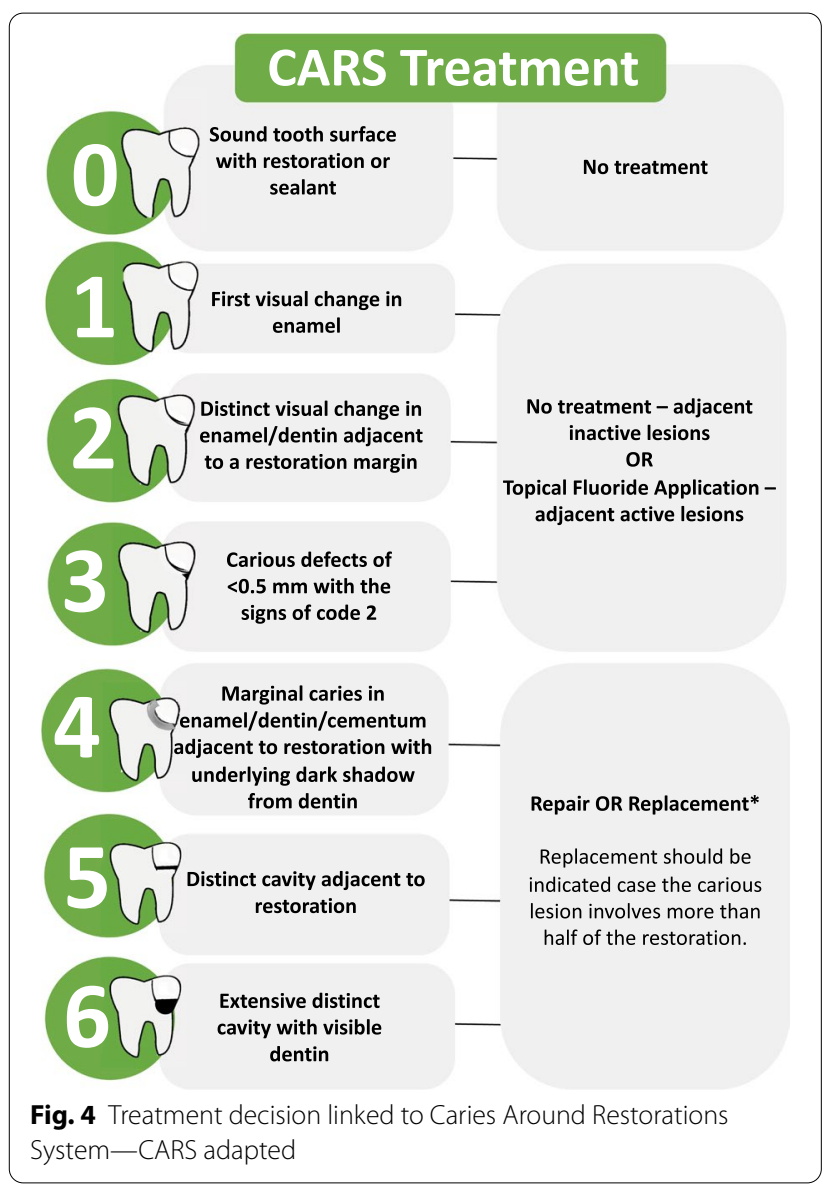

\section{Sample size}

The sample calculation was performed based on the primary outcome of the randomized clinical trial (percentage of restorations requiring reintervention). The calculation considered a 2-year failure rate of approximately $10 \%$ for occlusal restorations [16] and 30\% for occlusal-proximal restorations [17]. It was also assumed that about $10 \%$ of the replaced restorations and $14 \%$ of the restorations undergoing repair fail again [18]. Thus, estimating that half of the sample is from occlusal restorations, an operative reintervention requirement rate of $24 \%$ was estimated in 2 years. The number of 522 restorations was reached, based on an absolute difference of $10 \%$ between the groups, using a two-tailed test. As a participant can contribute with more than one restoration, $20 \%$ was added to this value $(n=626)$. Thus, considering a predetermined average of inclusion of 5 teeth per patient, and adding $20 \%$ to possible sample losses, a minimum number of 152 patients was reached to be included in the trial.

\section{Recruitment}

The recruitment will occur in the School of Dentistry, as it receives a considerable number of patients looking for dental treatment. An average of 200 patients seeks dental treatment attendance per month, totaling approximately 2400 patients per year. The patients will be aleatorily selected from this broader sample.

\section{Assignment of interventions \\ Allocation: sequence generation and concealment mechanism}

The random list will be generated via the website (www. sealedenvelope.com). The study participants will be examined, classified according to predetermined criteria determined by the randomization stratified by blocks, and then referred to the examiner to evaluate the restorations. The strata will be: (1) DMF-T index less or equal to 4 without caries activity; (2) DMF-T index less or equal to 4 with caries activity; (3) DMF-T greater than 4 without caries activity; and (4) DMF-T greater than 4 with caries activity.

To ensure allocation confidentiality, we will use opaque, sealed, and consecutively numbered envelopes. The allocated group will be revealed to the examiner before the start of the examination.

\section{Implementation}

A clinical operator not involved with the study design or evaluation will carry out the patient's initial exam. A pre-calibrated examiner will then examine the restorations and indicate the treatments based on the criteria defined by the randomization. The responsible for the dental treatment will perform the treatments based on the patient's treatment plan provided for them, without any access to the allocation group of the patient.

\section{Blinding}

The patients, care providers responsible for the dental treatment (undergraduate students and graduate students), and the assessor who will evaluate the outcomes will be blind to the participants' allocation group.

\section{Data collection, management, and analysis}

The follow-up assessments will be performed by a precalibrated examiner, who does not have previous contact with the patient and with last information about the allocation groups and treatments performed. The treatment needs will be established according to the demands of the patients.

The clinical data will be registered on sheets previously organized on Microsoft Excel Software. All data, except 


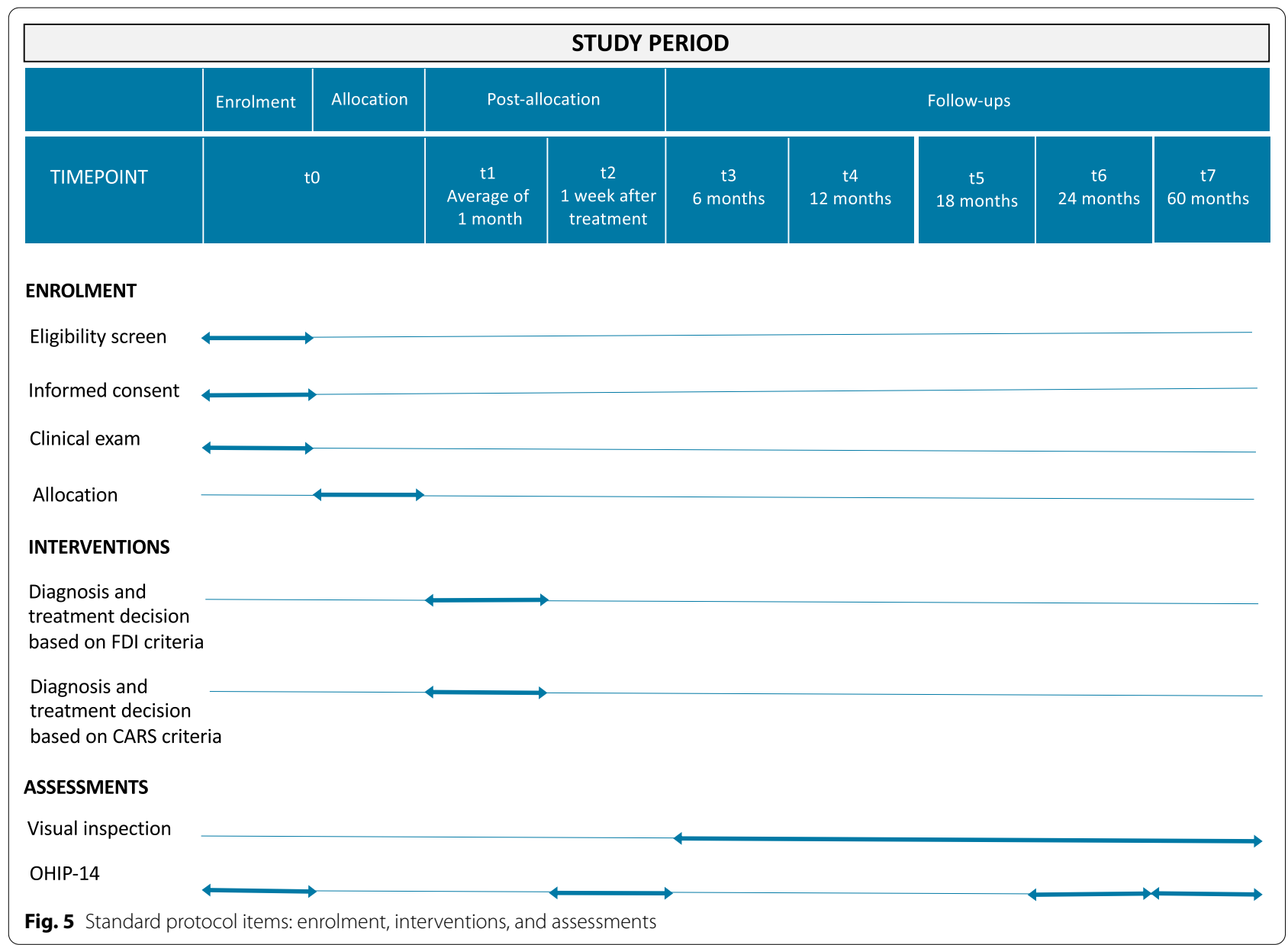

those that might reveal the participants' identities, will be shared in a public repository after accepting all manuscripts related to these studies.

The survival analysis will be used to analyze the primary outcome. Kaplan-Meyer graphs will be constructed, and the methods will be compared to each other with Cox regression with shared frailty. The calculation of sensitivity, specificity, and accuracy will consider the results obtained with the indices and the classification of the presence or not of caries lesion by the proposed reference standard. 95\% CI values will be calculated with adjustments as one individual may have more than one restoration included, using a suggestion previously published [19]. The sensitivity, specificity, and accuracy between the methods will be compared using multilevel analysis (3 levels: assessment, tooth, and child/adults). As also, for the comparisons between the treatment decisions obtained with the different criteria. The cost-effectiveness ratio will also be verified, considering as effect the prevention of the primary outcome, as well as other secondary endpoints of interest, and the cost spent to reach such a condition with each of the indices. For all tests, two-tailed analyzes will be used, considering a level of significance of $5 \%$. Analyzes will be performed using the statistical package Stata 15.0 (Stata Corp, College Station, USA).

\section{Monitoring \\ Data monitoring}

Independent regulation of data collection, management, and analysis will be assumed independently by MSC.

\section{Harms}

The procedures performed offer minimal risk to the oral health of patients. The adverse effects are represented by the teeth with pain episodes, postoperative sensitivity, tooth fracture during the restorative procedure, teeth requiring endodontic treatment, and exodontia. In dental treatment, the possibility of occurrence of these effects is usually present. 


\section{Auditing}

The data entered will be conducted by one of the authors of the study. The data will be weekly inspected. The inconsistencies will be verified, corrected, and registered.

\section{Ethics and dissemination}

\subsubsection{Research ethics approval}

This study was submitted and approved by the Ethical Committee from the School of Dentistry, Federal University of Pelotas (No. CAAE: 53463316.1.0000.5318).

\section{Consent and assent}

Informed consent will be provided and assigned by the participants.

\section{Confidentiality}

Identification numbers will be used to assure participant confidentiality during data analysis. Participants' files will be stored in a secure room.

\section{Availability of data}

The datasets used and/or analysed during the current study will be available from the corresponding author (MSC) on reasonable request.

\section{Ancillary and post-trial care}

The participants will receive dental treatment during and after the end of the study.

\section{Dissemination policy}

The findings will be reported in full through national and international journals, patient newsletters, and websites.

\section{Discussion}

The assessment of restorations in dentistry remains a challenge, even after many years of research and discussion $[5,11,20]$. The main point of debate is the detection of caries around restorations. The dentists do not show the same line of thinking about what is and what is not a caries lesion adjacent to the restoration. Also, there is a diversity of clinical criteria available to assess the caries lesions, which may influence the dentists' different opinions and on the treatment decisions taken $[6,7,11]$. In addition, there is a lack of evidence regarding the best criterion to detect secondary caries lesions.

The studies available about caries detection methods around restorations are in general studies of accuracy with cross-sectional experimental design [11, 14]. Still, there is a limited number of studies, with most of the studies being performed in vitro, showing a high risk of bias [11]. The accuracy studies are important to investigate the validity of the diagnostic method. Still, the best methods to be used in clinical practice should not be made based solely on these studies [11, 21, 22]. Besides, most studies fail to present clinical relevance and do not investigate patient-centered outcomes [11]. It is essential to explore which methods would assure more benefits to the patient's health [23]. And this is only possible through randomized clinical trials with proper follow-up periods.

Randomized clinical trials aiming to evaluate diagnostic tools are usual in the medical field. However, the same is not applied to dentistry, which shows a limited number of studies with this experimental design [24]. No previous study compared the accuracy of FDI and CARS criteria clinically to detect secondary caries on permanent teeth, and the impact of using the criteria on the restorative treatment decisions. It is also important to observe that in our study, the group based on the International Dental Federation (FDI) criteria included the recurrent caries criteria described by the FDI and the marginal staining and marginal adaptation criteria to complement the assessment of the restorations. This decision was based on the fact that many dentists and studies associate these two defects (marginal staining and marginal adaptation) with detecting caries lesions around the restorations [11].

The detection criteria are proposed and used to assess a particular condition and to aid in the selection of the most suitable treatment. Considering the restorative treatment, the proper treatment may range since the monitoring, repair, or replacement of the restoration [25]. Still, the correct diagnosis of caries around the restorations can lead to greater longevity of the restorative treatment, improving the patients' oral health, and reducing treatment costs [26]. A considerable burden on health care expenditure is attributed to the operative management of restorations due to the detection of secondary caries [5]. Also, the clinical criteria used to caries detection should be in line with the current philosophy of minimally invasive dentistry [27]. Using a method that tends to overtreatment, accelerating the repetitive restorative cycle is not desirable [28].

To the best of our knowledge, this will be the first study to assess the effect of two visual methods for evaluating caries lesions around restorations on the outcomes related to oral health in adults. The hypothesis under evaluation is that there will be a difference between the interventions established considering the outcomes centered on the restoration, tooth, or the patient.

\section{Trial status}

The trial is recruiting participants. The recruitment has been in progress from October 2016 until now. The end of the recruitment is planned for February 2020. Figure 6 presents the CaCIA trial logotype. 


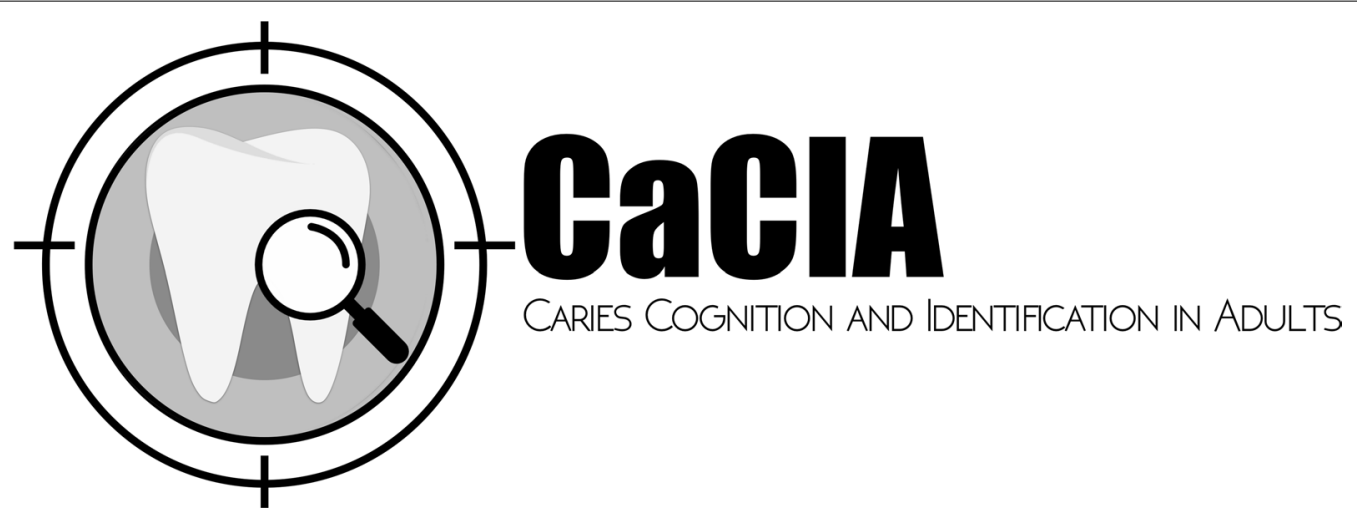

Fig. $6 \mathrm{CaClA}$ trial logotype

\section{Supplementary information}

Supplementary information accompanies this paper at https://doi. org/10.1186/s12903-020-01307-z.

Additional file 1. SPIRIT checklist.

\section{Abbreviations}

CaCIA: Caries cognition and identification in adults; CARDEC: Caries deection in children; CARS: Caries associated with restorations or sealants; Cl: Confidence interval; DMF-T: Decayed, missing, filled permanent teeth; FDI: World Dental federation; ICCMS: International Caries Classification and Management System; OHIP-14: Oral Health Impact Profile-14; SPIRIT: Standard Protocol Items for Clinical Trials; UFPEL: Federal University of Pelotas.

\section{Acknowledgements}

The authors would like to thank the CaCIA and CARDEC collaborative groups. Both collaborative groups have shared the ideas and collaborated to the planning and establishment of the present study. Members of each group can be found below:

CaClA collaborative group [29]

Ana Beatriz L. de Queiroz, Alessandra B. de Avila, Bruna O. Souza, *Cácia Signori, Camila R. Dias, Camila T. Becker, Eduardo T. Chaves, Eugênia C. Malhão, *Elenara F. de Oliveira, *Juliana Lays S. Uehara, Fernanda G. da Silva, Fernanda S. da Silva, Gabriel V. Lima Kucharski, Gabriele R. dos Santos, Julia M. Torres, Karoline V. A. Pinto, Laura L. Morel, Leonardo B. Weymar, Marcelo P. Brod, Maria F. Gamborgi, ${ }^{*}$ Maximiliano S. Cenci, Renata U. Posser, Thaís S. Vieira, *Vitor H. R. Digmayer, Wagner S. Nolasco, Wagner M. S. Leal, *Bruna L. P. Moro, Daniela P. Raggio, *Fausto M. Mendes, *Mariana M. Braga, Raiza D. Freitas.

CARDEC collaborative group-trial 3 [30]

Ana L. Pássaro, Annelry C. Serra, Antonio C. L. Silva, *Bruna L. P. Moro, Carolina P. Acosta, Caroline M. Laux, Cíntia S. Saihara, Daniela P. Raggio, *Fausto M. Mendes, Haline C. M. Maia, Isabel C. O. da Costa, Isabella R. de Almeida, Jhandira D. Yampa Vargas, Jonathan R. Garbim, José C. P. Imparato, Julia G. Freitas, Karina H. De Natal, Laura R. A. Pontes, Mariana Bifulco, *Mariana M. Braga, Mariana P. de Araújo, Mayume A. do Vale, Raiza D. Freitas, Renata M. Samuel, Rita Baronti, Rodolfo C. Oliveira, Simone Cesar, Tatiane F. Novaes, Tamara K. Tedesco, Thais Gimenez, Tathiane L. Lenzi, *Cácia Signori, ${ }^{*}$ Maximiliano S. Cenci, Kim Rud Ekstrand.

* These persons are also included as individual co-authors.

\section{Authors' contributions}

CS, BLPM, EFO, MMB, FMM, and MSC contributed to the conception of this trial. CS, FMM, and MSC designed the study. CS, JLSU and VRD are implementing the clinical trial. CS, JLSU and MSC are the trial coordinators. FMM and MSC are the principal investigators. CS is the examiner responsible for the treatment plans. CS, JLSU, and VRD are responsible for organizing and monitoring the treatments. The CaClA collaborative group [29] staff members are responsible for promoting, organizing and conducting all procedures related to the study. Members are secretaries, who disseminate information and organized the clinical, dental students, dentists and assistants who performed dental treatment and orientations for all study participants. All authors read and approved the final manuscript.

\section{Funding}

This study was financed in part by the Coordenação de Aperfeiçoamento de Pessoal de Nível Superior-Brasil (CAPES) —Finance Code 001 (Proc. \# 88881.134707/2016-01), and by the CNPq (National Council for Scientific and Technological Development) (productivity scholarship: Proc. \# 310340/20179). The institutions had no role in study design, data collection, analysis, decision to publish, or manuscript preparation.

\section{Availability of data and materials}

The dataset will be available in a public repository after the acceptance of the manuscripts.

\section{Ethics approval and consent to participate}

Ethical approval has been granted by the Local Ethics committee (No. 1.625.236/2016). The participants signed an informed consent term before participation in the study.

\section{Consent for publication}

Not applicable.

\section{Competing interests}

The authors state no financial and personal conflicts of interest that could have inappropriately influenced their work.

\section{Author details}

${ }^{1}$ Graduate Program in Dentistry, Federal University of Pelotas, Pelotas, RS, Brazil. $^{2}$ Department of Pediatric Dentistry, School of Dentistry, University of São Paulo, São Paulo, Brazil.

Received: 16 December 2019 Accepted: 31 October 2020 Published online: 10 November 2020

\section{References}

1. Seemann R, Flury S, Pfefferkorn F, Lussi A, Noack MJ. Restorative dentistry and restorative materials over the next 20 years: a Delphi survey. Dent Mater. 2014;30:442-8. https://doi.org/10.1016/j.dental.2014.01.013.

2. Kidd EA. Diagnosis of secondary caries. J Dent Educ. 2001;65:997-1000. https://doi.org/10.1001/archderm.1980.01640360020006.

3. Heintze SD, Rousson V. Clinical effectiveness of direct class II restorations-a meta-analysis. J Adhes Dent. 2012;14:407-31. https://doi. org/10.3290/j.jad.a28390. 
4. Letzel H. Survival rates and reasons for failure of posterior composite restorations in multicentre clinical trial. J Dent. 1989;17(Suppl 1):S10-7 (discussion S26-8).

5. Nedeljkovic I, De Munck J, Vanloy A, Declerck D, Lambrechts P, Peumans $M$, et al. Secondary caries: prevalence, characteristics, and approach. Clin Oral Investig. 2019. https://doi.org/10.1007/s00784-019-02894-0.

6. Alomari Q, Al-Saiegh F, Qudeimat M, Omar R. Recurrent caries at crown margins: making a decision on treatment. Med Princ Pract. 2009;18:18792. https://doi.org/10.1159/000204348.

7. Signori C, Laske M, Mendes FM, Huysmans M-CDNJM, Cenci MS, Opdam NJM. Decision-making of general practitioners on interventions at restorations based on bitewing radiographs. J Dent. 2018. https://doi. org/10.1016/j.jdent.2018.07.003.

8. Mjör I. Clinical diagnosis of recurrent caries. J Am Dent Assoc. 2005;136:1426-33.

9. Kidd EAM, Beighton D. Marginal ditching and staining as a predictor of secondary caries around amalgam restorations: a clinical and microbiological study. J Dent Res. 1995;74(5):1206-11.

10. Magalhães CS, de Freitas ABDA, Moreira AN, Ferreira EF. Validity of staining and marginal ditching as criteria for diagnosis of secondary caries around occlusal amalgam restorations: an in vitro study. Braz Dent J. 2009:20:307-13. https://doi.org/10.1590/S0103-64402009000400008.

11. Signori C, GimenezT, Mendes FM, Huysmans M-CDNJM, Opdam NJM, Cenci MS. Clinical relevance of studies on the visual and radiographic methods for detecting secondary caries lesions - a systematic review. J Dent. 2018. https://doi.org/10.1016/j.jdent.2018.05.018.

12. Hickel R, Peschke A, Tyas M, Mjör I, Bayne S, Peters M, et al. FDI World Dental Federation-clinical criteria for the evaluation of direct and indirect restorations. Update and clinical examples. J Adhes Dent. 2010;12:259-72. https://doi.org/10.3290/j.jad.a19262.

13. Pitts NB, Ismail Al, Martignon S, Ekstrand K, Douglas GV, Longbottom C. ICCMS $^{\text {TM }}$ guide for practitioners and educators 2016, p. 1-45.

14. Brouwer F, Askar H, Paris SSF. Detecting secondary caries lesions : a systematic review and meta-analysis. J Dent Res. 2015. https://doi. org/10.1177/0022034515611041.

15. Oliveira BH, Nadanovsky P. Psychometric properties of the Brazilian version of the Oral Health Impact Profile-short form. Community Dent Oral Epidemiol. 2005;33:307-14. https://doi.org/10.111 1/j.1600-0528.2005.00225.x.

16. Qvist V, Poulsen A, Teglers PT, Mjör IA. The longevity of different restorations in primary teeth. Int J Paediatr Dent. 2010;20:1-7. https://doi. org/10.1111/j.1365-263X.2009.01017.x.

17. Tedesco TK, Calvo AFB, Lenzi TL, Hesse D, Guglielmi CAB, Camargo $L B$, et al. $A R T$ is an alternative for restoring occlusoproximal cavities in primary teeth-evidence from an updated systematic review and meta-analysis. Int J Paediatr Dent. 2017;27:201-9. https://doi.org/10.1111/ ipd. 12252.
18. Moncada G, Fernández E, Mena K, Martin J, Vildósola P, De Oliveira OB, et al. Seal, replacement or monitoring amalgam restorations with occlusal marginal defects? Results of a 10-year clinical trial. J Dent. 2015;43:13718. https://doi.org/10.1016/j.jdent.2015.07.012.

19. Rao JNK, Scott AJ. A simple method for the analysis of clustered binary data. Biometrics. 1992;48:577. https://doi.org/10.2307/2532311.

20. Nedeljkovic I, Teughels W, De Munck J, Van Meerbeek B, Van Landuyt KL. Is secondary caries with composites a material-based problem? Dent Mater. 2015;31:e247-77. https://doi.org/10.1016/j.dental.2015.09.001.

21. Baelum V. What is an appropriate caries diagnosis? Acta Odontol Scand. 2010;68:65-79. https://doi.org/10.3109/00016350903530786.

22. GimenezT, Piovesan C, Braga MM, Raggio DP, Deery C, Ricketts DN, et al. Clinical relevance of studies on the accuracy of visual inspection for detecting caries lesions: a systematic review. Caries Res. 2015;49:91-8. https://doi.org/10.1159/000365948.

23. Sackett DL, Haynes RB. The architecture of diagnostic research. BMJ 2002;324:539-41. https://doi.org/10.1136/bmj.324.7336.539.

24. Mendes FM, Pontes LRA, GimenezT, Lara JS, de Camargo LB, Michel-

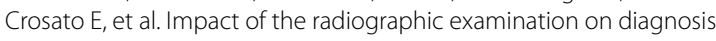
and treatment decision of caries lesions in primary teeth-the Caries Detection in Children (CARDEC-01) trial: Study protocol for a randomized controlled trial. Trials. 2016. https://doi.org/10.1186/s13063-016-1196-5.

25. Wilson N, Lynch C, Brunton P, Hickel R, Meyer-Lueckel H, Gurgan S, et al. Criteria for the replacement of restorations: Academy of Operative Dentistry European Section. Oper Dent. 2016;41:S48-57. https://doi. org/10.2341/15-058-O.

26. Schwendicke F, Brouwer F, Paris S, Stolpe M. Detecting proximal secondary caries lesions: a cost-effectiveness analysis. J Dent Res. 2015;95:152-9. https://doi.org/10.1177/0022034515617937.

27. Frencken JE, Peters MC, Manton DJ, Leal SC, Valeria V, Eden E. Minimal Intervention Dentistry (MID) for managing dental caries - a review. Int Dent J. 2012;62:223-43. https://doi.org/10.1111/idj.12007.

28. Qvist V. Longevity of restorations: the death spiral. In: Fejerskov O, Kidd EAM, editors. Dental caries: the disease and its clinical management. London: Oxford (UK): Wiley-Blackwell; 2015. p. 387-404.

29. CaClA collaborative group. https://sites.usp.br/cardec/info/grupos_parce iros/cacia-trial-1/grupo-de-colaboradores/. Accessed 24 Sep 2020.

30. CARDEC collaborative group—trial. https://sites.usp.br/cardec/pesqu isas_de_diagnostico/cardec-03/impacto-de-duas-estrategias-de-diagn ostico-de-lesoes-de-carie-ao-redor-de-restauracoes-em-dentes-decid uos/grupo-de-colaboradores/. Accessed 24 Sep 2020.

\section{Publisher's Note}

Springer Nature remains neutral with regard to jurisdictional claims in published maps and institutional affiliations.
Ready to submit your research? Choose BMC and benefit from:

- fast, convenient online submission

- thorough peer review by experienced researchers in your field

- rapid publication on acceptance

- support for research data, including large and complex data types

- gold Open Access which fosters wider collaboration and increased citations

- maximum visibility for your research: over $100 \mathrm{M}$ website views per year

At BMC, research is always in progress.

Learn more biomedcentral.com/submissions 